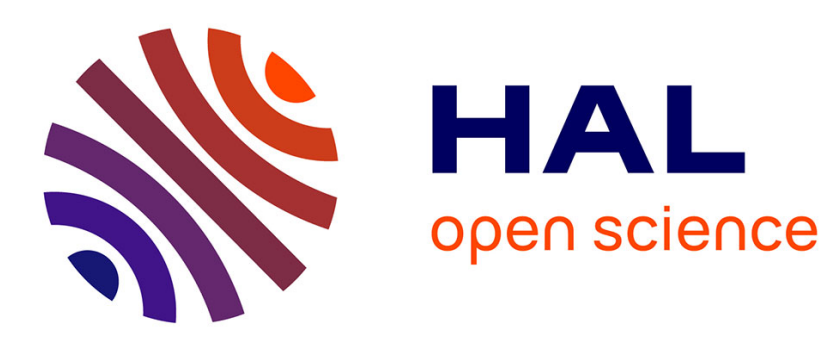

\title{
The Interaction of Global Networks in Their Evolutions: A Longitudinal Case Study
}

\author{
Yang Cheng, Ruihong Gao
}

\section{To cite this version:}

Yang Cheng, Ruihong Gao. The Interaction of Global Networks in Their Evolutions: A Longitudinal Case Study. IFIP International Conference on Advances in Production Management Systems (APMS), Aug 2018, Seoul, South Korea. pp.215-222, 10.1007/978-3-319-99707-0_27 . hal-02177841

\section{HAL Id: hal-02177841 \\ https://hal.inria.fr/hal-02177841}

Submitted on 9 Jul 2019

HAL is a multi-disciplinary open access archive for the deposit and dissemination of scientific research documents, whether they are published or not. The documents may come from teaching and research institutions in France or abroad, or from public or private research centers.
L'archive ouverte pluridisciplinaire HAL, est destinée au dépôt et à la diffusion de documents scientifiques de niveau recherche, publiés ou non, émanant des établissements d'enseignement et de recherche français ou étrangers, des laboratoires publics ou privés. 


\title{
The interaction of global networks in their evolutions: a longitudinal case study
}

\author{
Yang Cheng $^{1 *}$ and Ruihong $\mathrm{Gao}^{2}$ \\ ${ }^{1}$ Department of Materials and Production, Aalborg University, Denmark \\ ${ }^{2}$ Faulty of Business Administration, Osaka University of Economics, Japan \\ *Corresponding author: cy@business.aau.dk
}

\begin{abstract}
Based on a longitudinal study of two companies, this paper investigates the evolution of manufacturing, supply, and strategic networks and suggests it can be viewed as a long-term, stepwise, expansive, iterative and interactive process and thereby, can be called "interactive evolution of constructs and networks". It is further found that the evolution of plants and manufacturing networks is more closely linked with the evolution of suppliers and supply networks, and vice versa; the evolution of JVs and strategic networks can be linked with the evolutions of plants/suppliers and manufacturing/supply networks, but depending on the purposes behind the establishment of JVs. Finally, this paper proposes short-term and long-term solutions to manage different networks holistically.
\end{abstract}

Keywords: Manufacturing Network, Supply Network, Strategic Network.

\section{Introduction}

Since the 1980s, it has been impossible for manufacturing companies to withstand the trend of globalisation. There are generally three modes for manufacturers to globalise their operations [1]. The first mode is the so-called dominant equity mode, which allows full ownership and control. The explosively increased FDI have further resulted in the widespread restructuring of manufacturing systems, moving from a focus on the plant to one on the manufacturing network. A manufacturing network, defined as a coordinated aggregation (network) of intra-firm plants/factories located in different places, is normally studied as a wholly owned and internal network in which all plants are under full financial control [1,2].

Meanwhile, it has also become more accepted for manufacturing companies to globalise their operations by following the second mode, i.e. the diffused governance mode, which lacks ownership and has only limited possibilities for control. This development has further pushed companies into new relationships and made the subjects of supply chain/network become more relevant and required [3]. A supply network, defined as a network of connected and interdependent organisations mutually and cooperatively working together to manage the flow of goods and services from original supply sources to end users, is normally analysed as an external 
(inter-firm) network with facilities owned by different organisations and characterised by sets of purposeful and connected exchange relationships [1].

The last mode is the balanced mode, which emphasizes shared ownership, equal partnership and balanced contracts, and appears in the forms of strategic alliance (SA) and joint venture (JV). The prevalence of SA and JV further stimulates more considerations on strategic networks. A strategic network exists within and is an integral part of the overall inter-firm supply network. It goes beyond intra-firm manufacturing network and refers to inter-firm collaboration with external partners, but it mainly addresses long-lasting inter-organisational relationships [4].

The rationale for choosing specific modes is not necessarily guided by the same principles and the managements of manufacturing network, supply network, and strategic network are usually discussed independently [2, 3]. The existing studies generally do not adequately address in a systematic manner the complex interactions between the evolutions of different networks. Nevertheless, any company in the practice that intends to establish a global operations structure might adopt three modes simultaneously. Therefore, this paper aims to address such a cognitive gap and develop an in-depth understanding of the interactions between the evolutions of manufacturing network, supply network, and strategic network by exploring RQ1, i.e. how the evolution of one type of network affects other networks. This issue has become ever more urgent to manufacturing companies in the context of today's business environment. Companies could be out of business if they do not analyse and adjust the operations of their networks holistically and proactively. Thus, this paper also aims to explore RQ2, i.e. how to manage different networks in a holistic way.

\section{Literature review}

\subsection{Manufacturing, supply, and strategic Networks}

Setting its root in the disciplines of operations management, the research on manufacturing network seeks to extend the boundaries of traditional manufacturing systems from a single plant towards a multi-plant system and further, to globally dispersed and coordinated plant networks [5]. Thus, manufacturing network can still be seen as a manufacturing system, but certainly with many different characteristics from the classic model. Two types of decisions can generally be distinguished related to manufacturing network: those concerning "configuration", which primarily addresses structural decisions to design a network, and those related to "coordination", which primarily addresses infrastructural links among plants [1].

Similar to manufacturing network, supply network also has its own missions, architectures, mechanisms, and strategy processes, but, differently, the research on supply network sets its roots in physical distribution and material management. It tends to analyse the network as external with facilities owned by different organisations [1,3] and focuses on the links between the nodes (and specifically distribution nodes), whereas manufacturing network research tends to focus on the (manufacturing) nodes themselves [1]. Accordingly, compared to studies on manufacturing network, the research in the field of supply network has quite different 
focuses in addition to physical distribution and material management, such as customer relationship management, customer service management, demand management, procurement, and so on. Similar to other areas in management, these focuses appear to generally fall into two broad streams: the "hard" system-dominated focuses that deal with technological and infrastructural issues and the "soft" peoplefocused focuses that deal with social relationships [6].

SAs and JVs are integral part of the overall inter-firm supply network and as such, the management of them is directly related to the characteristics of these inter-firm supply networks and the embeddedness a firm exhibits in such networks. Accordingly, recent academic inquiry has directed attention to examining SA and JV from a network perspective [4]. The strategic network area is examined by different streams of research: (1) the emergence of strategic networks, answering why and how firms build strategic networks [7]; (2) the configuration of strategic networks; (3) the formation of strategic networks, exploring the formation of relationships and the formation processes [8]; and (4) the management of strategic networks with the emphases on the capability of strategic network, management approaches and tools, and the performance assessment of strategic networks [7, 8].

\subsection{Literature analysis, theoretical gaps, and research questions}

According to the above review, it is obvious that the literature on manufacturing network, supply network, and strategic network is well established, but three research gaps can still be identified. First, according to the definitions of networks stated early in the introduction, intra-firm plant, inter-firm SA and JV, and other inter-firm organisations can be respectively viewed as the basic constructs of manufacturing network, strategic network, and supply network. However, the two levels of analysis, i.e. construct level and network level, are usually discussed independently to reduce the complexity of research on manufacturing, strategic, and supply networks. Some of more recent studies in the area of manufacturing network attempted to address this gap, but they are still limited in the domain of manufacturing network. To our knowledge, there is no research addressing how the development of SAs, JVs, and other inter-firm organisations affects the plants within a manufacturing network and leads to changes of that manufacturing networks, or vice versa. This actually implies the second research gap, i.e. the studies on manufacturing, strategic, and supply networks are limited within their own domains, and the interaction between different networks is not well addressed. However, there is abundant empirical evidence that the manufacturing industry is currently transforming from plant based manufacturing system centralised or dispersed within one country to plant networks with geographic dispersion and operational integration owned by a multinational corporation and from the traditional vertically-integrated value chain to collaboration between specialised independent companies [3]. Thus, it is important to discuss different networks in a holistic framework. Some studies have addressed this issue [5, 9], but they neglect the fact that individual subsidiaries and affiliates, joint ventures, strategic alliances, independent suppliers, and distribution channels have gradually developed to be manufacturing networks, strategic networks, and supply networks, which is the third 
gap. Addressing the above gaps, this paper aims to investigate the interaction between manufacturing, strategic, and supply networks in their evolution, specifically paying attention to both construct and network levels. Two research questions listed in the Introduction are expected to be answered.

\section{Research methodology}

In order to answer the "how" questions formulated above, the case study was selected as the primary research method and mainly used for an explorative purpose [10]. To obtain the understandings on the interactions between different networks in their evolution in depth, this paper chose to specifically focus on a sample of two case companies from the same industry, i.e. machine tool industry, but with different size and from different countries. One of the case companies, i.e. FFG, is the third biggest manufacturer of machine tools in the world, in terms of more than 5000 employees, 50 production bases in 10 countries, and 37 machine tool brands. The other case company, i.e. TM, is relatively small with around 510 employees, but has been developing and producing machine tools since 1961. In fact, TM is one of the most important partners of FFG. They have established several JVs together, which brings the opportunity to investigate the development of a strategic network from both sides.

Empirical data was collected between 2010 and 2017 following a three-step approach. First, longitudinal secondary sources were analysed. Second, the researchers visited the headquarters and the facilities of two case companies in China, Taiwan, Japan, and Italy to conduct interviews. More than 20 interviews were conducted with group chairmen, presidents, general managers, production managers, and global sourcing managers, each of which typically spanned three to four hours. Finally, combing the data from different sources, case reports were written, returned to the interviewees for verification, and finalised after several rounds.

Data analysis was carried out simultaneously with data collection, creating an iterative process between the interviews, literature reviews and analysis. More specifically, it followed the framework analysis approach proposed by [10].

\section{Case analysis and discussion}

\subsection{Interactive evolution of constructs and networks}

In FFG and TM, the evolution of their plants and manufacturing networks generally followed the approach described in [11]. In both companies, their overseas plants were mainly established for low-cost labour and market proximity, but they evolved gradually and simultaneously. From a plant perspective, these plant evolutions were often interdependent. As the portfolios of products and processes flowed among plants, strategic roles of related plants (i.e. transferors and receivers) were being changed simultaneously and gradually. From a manufacturing network perspective, inter-related evolutions of plants can also lead to the portfolio of plants being changed from time to time, which represented the transformation of the configurations of 
manufacturing networks and further triggered the redevelopment of coordination mechanism of manufacturing networks.

Meanwhile, the evolution of plants and manufacturing networks in two case companies further influenced, as well as being influenced by, the evolution of suppliers and supply networks. When FFG established its first plant in China, it initially imported components from Taiwan and Japan, but soon asked its Taiwanese and Japanese suppliers to relocate to China, in order to support its local production operations. Differently, TM chose to establish a JV with FFG and heavily rely on the suppliers developed by FFG when it entered the Chinese market. Otherwise, it might also have to import components from Japan. Nevertheless, TM treated the JV, i.e. FTChina, as its own plant. After accumulating proper capabilities, both FT-China and the Chinese plant of FFG were given more responsibilities to produce more products by using more complicated processes. Along with more products/processes being transferred to their Chinese facilities, it became natural for FFG and TM to have more local suppliers, since for FFG not all of its suppliers in Taiwan and Japan followed its footprint and started operating in China; and for TM more cost reduction might be achieved by engaging more local suppliers. Nevertheless, both companies had to help local suppliers to develop their capabilities, in order to supply their specific production. After accumulating their capabilities and proving their viability, the Chinese suppliers were given more production tasks and used to replace the suppliers from other places, which at the same time led to the changes in the supply network configuration. Meanwhile, the development of the Chinese suppliers in turn triggered more products/processes being transferred to the Chinese plants and FT-China, making them responsible for producing more kinds of and more complicated products. TM even outsourced more production activities to its suppliers. The manufacturing networks of both companies were accordingly, reconfigured.

Furthermore, the evolution of JVs and strategic networks in two case companies was also closely linked with the evolutions of plants/suppliers and manufacturing/supply networks, but in different manners depending on the purposes behind the establishment of JVs. First, FFG established FT-China with TM, as well as the other JV with TM and a Japanese supplier, for the purpose of learning. The development of these JVs gradually facilitated the other plants of FFG improving their capabilities by transferring technological and managerial knowledge to them. In this case, these JVs were more like centres of excellence to FFG and hereby contributed to the evolution of its plants and manufacturing network directly. Second, TM established JVs mainly for the purpose of initially penetrating into new markets and later expanding in those markets. It treated JVs as its own plants and as a part of its manufacturing network. Along with the development of these JVs, more products/processes were transferred from TM's plants to it, which accordingly led to the evolution of plants/suppliers and manufacturing/supply networks of TM as discussed above. Third, similarly, FFG established the other JV in Japan with TM (i.e. FT-Japan) for the purpose of penetrating into new market. Nevertheless, the development of this JV did not have much influence on the evolution of plants/suppliers and manufacturing/supply networks of both companies, since this JV was established mainly for selling FFG's products in Japan and ensuring TM could 
provide necessary after-sales services and maintenance. Finally, FFG also established JVs with some of its Chinese suppliers for the purpose of helping them improving their capabilities, which accordingly contributed to the evolution of these suppliers and further led to the reconfigurations of supply network, as well as the evolution of plants and manufacturing network, as discussed above. Nevertheless, no matter which purposes JVs were established for, their development and success generally triggered both companies to establish more JVs and extend their strategic networks.

\subsection{How to manage different networks in a holistic way?}

It is indeed difficult to manage different networks in a holistic way, as there are too many elements that need to be considered. Alternatively, we can attempt to address what are the unique benefits that might not be obtained without running different networks holistically. Then, the question becomes identifying the unique benefits and ensuring companies can obtain them from operating different networks holistically.

In the near-term, companies can benefit from operating different networks holistically in terms of three aspects, as demonstrated in the empirical cases. First, operating different networks holistically allows plants, suppliers, and JVs learn more from each other, and thereby accelerates learning and moves down the learning curve quickly. Sharing knowledge among different constructs and networks is essential for obtaining this benefit. Second, operating different networks holistically enhances the ability of a company to pool resources, capacities, and capabilities in multiple network constructs, and hence copes with variability of demand and production processes. Sharing resources, capacities, and capabilities is the key for enjoying this benefit. Third, operating different networks holistically facilitates more coordinated planning and responsiveness among different network constructs, and thereby reduces potential mistakes and creates better alignments between manufacturing, supply, and strategic networks. In this case, information sharing among different constructs and networks is necessary. Comparatively speaking, it is obvious that the key to obtain these benefits is Sharing. Then, exploring how to stimulate sharing among different networks is pivotal for answering how to manage different networks in a holistic way in near-term. The empirical case study of FFG provides some good demonstrations, showing the sharing among different networks can be stimulated from both configuration and coordination perspectives. From the configuration perspective, FFG established three manufacturing bases in Hangzhou, China. It not only placed all its Chinese plants in these manufacturing bases, but also invited its suppliers and partners to place their plants there. In doing so, FFG would benefit from cluster effect, facilitate sharing among different networks, and ensure that every entity in the networks can work together in a mutually complementary multifaceted manner. From the coordination perspective, FFG appointed regional managers, whose responsibilities included visiting plants, suppliers, and JVs in the regions in a regular basis, tracking their development, acting as a broker to coordinate them and as a bridge to link them with other regions and headquarters.

In the long-term, companies can benefit from managing different networks in a holistic way, only when they continuously optimise the allocation of production and 
procurement among their plants, suppliers, and JVs. In order to continuously optimise the allocation of production and procurement among their plants, suppliers, and JVs, companies have to monitor various factors frequently, integrate them as a whole, distinguish or predict their every (possible) change, address the implications of their evolution and interaction. The factors that can influence the allocation of production and procurement among plants, suppliers, and JVs are as follows: (1) The development of product and process. In FFG and TM, new products and processes are normally developed, improved, and manufactured in their lead-plants or JVs initially. During the course of their life cycles, their production gradually becomes mature and standard, which further enable transferring them to other plants, JVs, and even suppliers; (2) Capability development of plant, supplier, and JV. As demonstrated in FFG and MT, plants, suppliers, and JVs normally start their operations from simple products and basic processes due to the fact that they do not have the capabilities to handle complicated production tasks. However, they are able to develop their own competencies based on the accumulation of their experiences with simple operations and the supports from headquarters and partners. Once they are capable and qualified, more (complicated) production activities can be allocated to them, both intra-firm and inter-firm; (3) Change of external environment of construct location. Location conditions of plants, suppliers, and JVs change dynamically, which might have positive and negative impacts on the allocation of production and procurement. For example, TM established and moved some of its production to FT-China, because on the one hand the Japanese domestic market has become mature and entered into a decreasing phase; on the other hand the Chinese market has grown rapidly. Similarly, FFG established its first plant in China due to the advantage of low cost labour and the potential of Chinese markets. Afterwards, it continuously upgraded its Chinese plants because China developed at a faster pace in the last decades. This also explained why TM set up International Purchasing Office in China, purchased more from Chinese and Taiwanese suppliers, and extended its supply networks in China and Taiwan rather than in Thailand, even though it also produced there. Nevertheless, the above three factors enable the re-allocation of production and procurement activities, but real changes have to be eventually driven by top management when they recognise opportunities and attempt to make relevant (4) high-level strategic decisions, including relocating production activities among existing plants, suppliers, and JVs; relocating procurement activities among existing suppliers; establishing new plants and JVs to accommodate relocated production; acquiring/merging plants and JVs to accommodate relocated production; closing plants and JVs; supporting the development of plants, suppliers, and JVs.

\section{Conclusion}

Based on a longitudinal study of two companies, this paper bridges the gaps identified in the existing literature about the evolution of manufacturing, supply, and strategic networks by exploring how the evolution of one type of network affects other networks and how to manage different networks in a holistic way. It is suggested that 
the evolution can be viewed as a long-term, stepwise, expansive, iterative and interactive process and, thereby, can be called "interactive evolution of constructs and networks". It is further found that the evolution of plants and manufacturing networks is more closely linked with the evolution of suppliers and supply networks, and vice versa; the evolution of JVs and strategic networks can be linked with the evolutions of plants/suppliers and manufacturing/supply networks, but depending on the purposes behind the establishment of JVs. Finally, this paper proposes short-term and longterm solutions to manage different networks holistically.

This paper's findings and discussions were based on case studies of one Taiwanese and one Japanese companies. The small sample size obviously limits generalisation of the presented conclusions. Besides, the evolution of global networks is closely related to the activities across international boundaries, it becomes imperative to have discussions on the variables such as international culture, administration, geographical challenges and economic situation.

\section{References}

1. Cheng, Y., Farooq, S., \& Johansen, J.: International manufacturing network: past, present, and future. International Journal of Operations \& Production Management, 35 (3), 392-429 (2015).

2. Cheng, Y., Chaudhuri, A., \& Farooq, S.: Interplant coordination, supply chain integration, and operational performance of a plant in a manufacturing network: a mediation analysis. Supply Chain Management: An International Journal, 21(5), 550-568 (2016).

3. Cheng, Y., \& Johansen, J.: Operations network development: internationalisation and externalisation of value chain activities. Production Planning \& Control, 25(16), 13511369 (2014).

4. Carnovale, S., Rogers, D. S., \& Yeniyurt, S.: Bridging structural holes in global manufacturing equity based partnerships: A network analysis of domestic vs. international joint venture formations. Journal of Purchasing and Supply Management, 22(1), 7-17 (2016).

5. Shi, Y., \& Gregory, M.: Emergence of global manufacturing virtual networks and establishment of new manufacturing infrastructure for faster innovation and firm growth. Production planning \& control, 16(6), 621-631 (2005).

6. Burgess, K., Singh, P. J., \& Koroglu, R.: Supply chain management: a structured literature review and implications for future research. International Journal of Operations \& Production Management, 26(7), 703-729 (2006).

7. Wassmer, U.: Alliance portfolios: A review and research agenda. Journal of management, 36(1), 141-171 (2010).

8. Grimm, C., Knemeyer, M., Polyviou, M., \& Ren, X.: Supply chain management research in management journals: A review of recent literature (2004-2013). International Journal of Physical Distribution \& Logistics Management, 45(5), 404-458 (2015).

9. Ernst, D., \& Kim, L.: Global production networks, knowledge diffusion, and local capability formation. Research policy, 31(8-9), 1417-1429 (2002).

10. Yin, R.: Case study research: Design and methods. Sage Publications, Inc (2003).

11. Cheng, Y., Farooq, S., \& Johansen, J.: Manufacturing network evolution: a manufacturing plant perspective. International Journal of Operations \& Production Management, 31(12), 1311-1331 (2011). 